\title{
WHAT CAN BE LEARNED FROM SKELETONS THAT MIGHT INTEREST ECONOMISTS, HISTORIANS AND OTHER SOCIAL SCIENTISTS?
}

\author{
Richard H. Steckel \\ Working Paper 9519 \\ http://www.nber.org/papers/w9519 \\ NATIONAL BUREAU OF ECONOMIC RESEARCH \\ 1050 Massachusetts Avenue \\ Cambridge, MA 02138 \\ February 2003
}

The views expressed herein are those of the author and not necessarily those of the National Bureau of Economic Research.

(O2003 by Richard Steckel. All rights reserved. Short sections of text not to exceed two paragraphs, may be quoted without explicit permission provided that full credit including Onotice, is given to the source. 
What Can Be Learned from Skeletons that Might Interest Economists, Historians and Other Social Scientists?

Richard H. Steckel

NBER Working Paper No. 9519

February 2003

JEL No. N0, O0

\begin{abstract}
$\underline{\text { ABSTRACT }}$
Economists and other scholars have long sought to measure and analyze long-term trends and differences in social performance. Average stature supplements and lengthens data series on traditional measures of life expectancy and real GDP per capita. This paper presents a methodology for using skeletal remains to greatly extend the chronological and cultural reach of anthropometric measures. Bones are widely available for study and unlike stature, they portray health over the life cycle, depicting both childhood and processes of aging and degeneration. The paper briefly explains seven skeletal measures widely used in physical anthropology and discusses procedures for summarizing community health in the form of an index. Results are based on a sample of over 12,000 individuals who lived at 65 localities in the Western Hemisphere over the past several millennia. Results challenge conceptions of the pre-Columbian disease environment, and the methods can be used to test models of very long-term economic growth and to study important aspects of human welfare during climate change.
\end{abstract}

Richard H. Steckel

Economics and Anthropology Departments

Ohio State University

Columbus, OH 43210

and NBER

steckel.1@osu.edu 
Economists and historians generally agree on the considerable value of investigating long-term trends and differences in the standard of living or quality of life. They have displayed ingenuity in estimating and analyzing GNP and life expectancy for many countries back to the nineteenth century (or earlier, in a few cases). Using height data from military records and other sources, anthropometric historians have extended the study of health aspects of the standard of living into the eighteenth century.

This paper discusses a methodology for considerably expanding the chronological and geographic reach of anthropometric history by utilizing skeletal remains as the basic data source. Bones are far more informative about health than heights alone and they are available in substantial quantities for people who lived in many parts of the world over the past several millennia. Among other things, these remains depict aspects of health over the life cycle, as opposed to the growing years in the case of stature, and they are available for women and for children, two groups whose condition and activities are often excluded from traditional historical sources such as military documents, voting tallies and property records.

Skeletons can therefore be used to chart important aspects of the human experience, embracing its enormous diversity in the lengthy journey from the era of hunter-gathers onward to settled agriculture, the rise of cities, global exploration and colonization, and eventual industrialization. Study of the possible causes and consequences of these changes is facilitated by archaeological artifacts, evidence collected by climate historians, GIS (Geographic Information System) data, and a variety of historical records. Sampling issues inevitably arise in their comparative study and there are ambiguities in interpreting this biological evidence. Confidence in the approach is bolstered, however, by comparing results with patterns of health that are well established from other sources.

\section{Skeletal Indicators of Health}

Skeletal furnish the best and, in many cases, the only picture of health available over the millennia. To understand this evidence it is useful to begin with a general discussion of skeletal manifestations of stress. ${ }^{1}$ Unlike dental enamel, bones are living tissues that receive blood and adapt to mechanical and physiological stress. Habitual physical activity that requires 
exertion leads to a readily visible expansion of the related muscle attachments on the skeleton. If the action is repetitive in a particular direction, the bones adapt to the load by following Wolff's Law, or thickening in the direction of the plane of motion. ${ }^{2}$ Hunter-gatherers who walked long distances, for example, had oval-shaped femurs but these bones are nearly circular among settled agriculturalists who had diverse activity patterns. Similarly, professional athletes such as tennis players and baseball pitchers develop extensive muscles, tendons and bones in the shoulders and arms on the side that they use.

Net nutrition has been an effective concept for understanding the environmental factors that influence human growth. The body is a biological machine that requires fuel for basal metabolism, to perform work and to combat infection, all of which claim dietary intake. ${ }^{3}$ If net nutrition is insufficient, growth slows or ceases, and linear growth of the skeleton is stunted if the deprivation is chronic and severe.

In principle, anthropologists could use any bone to estimate stature but the femur is most widely used because it is often well preserved and is easily measured. It also has the greatest correlation with stature in part because it comprises about one quarter of standing height. Seeking information useful in forensics, Mildred Trotter and Goldine Gleser (1952) estimated the relationship between the two variables using femur lengths of the deceased whose living height was known from muster rolls or other sources. The equations vary somewhat by sex (females are a few centimeters shorter than males for a given femur length), and accurate height estimates require anthropologists to draw upon sexually dimorphic characteristics of the pelvis and the skull that appear in adolescence. Growth plates obfuscate the bone lengths of juveniles, and height estimates are correspondingly problematic until the bony components of the femur fuse late in the teenage years.

As a group, physical anthropologists collect hundreds of skeletal measures, many of which are very specialized in nature and some of which reflect rare or unusual forms of physiological stress. ${ }^{4}$ In designing a study of community health with a large number of collaborators, it is important to select general health indicators that are understood and reported by virtually all physical anthropologists, regardless of specialty. In The Backbone of History: 
Health and Nutrition in the Western Hemisphere (Richard H. Steckel and Jerome C. Rose, 2002), which investigated skeletal health over the past several thousand years, these included three indictors of health during childhood (stature, linear enamel defects, and skeletal signs of anemia), two measures of decline among adults (dental decay and degenerative joint disease), and two that could affect any age group, but are more prevalent among older children and adults (skeletal infections and trauma). Stature has already been discussed as a child health indicator, and the others are briefly explained below (for more information see Clark S. Larsen (2000) and Tim D. White and Pieter A. Folkens, 2000 and references therein).

A. Enamel hypoplasias (linear enamel defects). Hypoplasias are lines or pits of enamel deficiency commonly found in the teeth (especially incisors and canines) of people whose childhood was biologically stressful. They are caused by disruption to the cells (ameloblasts) that form the enamel. The disruption is usually environmental, commonly due to either poor nutrition or infectious disease or a combination of both. Although nonspecific, hypoplasias are informative about physiological stress in childhood in archaeological settings. B. Indicators of iron deficiency anemia (porotic hyperostosis and cribra orbitalia). Iron is essential for many body functions, such as oxygen transport to the body's tissues. In circumstances where iron is deficient—owing to nutritional deprivation, low body weight, chronic diarrhea, parasite infection, and other factors - the body attempts to compensate by increasing red blood cell production. The skeletal manifestations appear in those areas where red blood cell production occurs, such as in the flat bones of the cranium. The associated pathological conditions are sieve-like lesions called porotic hyperostosis and cribra orbitalia for the cranial vault and eye orbits, respectively. The lesions can also be caused by other factors, ${ }^{2}$ but iron deficiency is among the most common causes. In infancy and childhood, iron deficiency anemia is associated with impaired growth and delays in behavioral and cognitive development. In adulthood, the condition is associated with limited work capacity and physical activity.

C. Dental health. Dental health is an important indicator both of oral and general health. Dental health in archaeological skeletons is assessed from dental caries, antemortem 
tooth loss, and abscesses. Dental caries is a disease process characterized by the focal demineralization of dental hard tissues by organic acids produced by bacterial fermentation of dietary carbohydrates, especially sugars. In the modern era, the introduction and general availability of refined sugar caused a huge increase in dental decay. In the more distant past, the adoption of agriculture led to a general increase in tooth decay, especially from the introduction of maize. The agricultural shift and the later use of increasingly refined foods have resulted in an increase in periodontal disease, caries, tooth loss, and abscesses.

D. Degenerative joint disease. Degenerative joint disease (DJD) is commonly caused by the mechanical wear and tear on the joints of the skeleton due to physical activity. Generally speaking, populations engaged in habitual activities that are physically demanding have more DJD (especially buildup of bone along joint margins and deterioration of bone on articular joint surfaces) than populations that are relatively sedentary. Studies of DJD have been valuable in documenting levels and patterns of activity in past populations.

E. Skeletal infections (osteoperiostitis). Skeletal lesions of infectious origin, which commonly appear on the major long bones (especially the tibia), have been documented worldwide. Most of these lesions are found as plaque-like deposits from periosteal inflammation, swollen shafts, and irregular elevations on bone surfaces. Most lesions are nonspecific but they often originate with Staphylococcus or Streptococcus organisms. These lesions have proven very informative about patterns and levels of community health in the human past.

F. Trauma. Fractures, weapon wounds, and other skeletal injuries provide a record of accidents or violence. Accidental injuries, such as ankle and wrist fractures, reflect difficulty of terrain and the hazards of specific occupations. Injuries caused by violence, such as weapon wounds or parry fractures of the forearm, provide a barometer of domestic strife, social unrest, and warfare.

\section{Summarizing Community Health}

Demographers and medical personnel quantify health in many ways, but all agree that it has two important elements: length of life and morbidity. The methodology for measuring 
the first, using life expectancy at birth (and at other ages), was refined during the nineteenth century but much less agreement exists on principles for the second. While death is usually well-defined, morbidity is much less precise. The incidence of various chronic diseases, days lost from school or work, and assessments of physical capacity are used, but all have conceptual limitations. Moreover, gathering reasonably comprehensive morbidity information that is accurate is often time-consuming and expensive. Significant progress on the problem may be made eventually by using devices that transmit information from receptors implanted in the body.

How effective are skeletons in capturing the elements of health? At most localities or burial sites, a useful but incomplete picture is available for morbidity. Estimates of life expectancy will be improved by new techniques of aging, but remain hazardous without good contextual information about the population from archaeological and other sources. Lack of information on life expectancy is less damaging than it might appear for the study of health, however. To the extent that morbidity and mortality are positively correlated, health can still be indexed or ranked across sites by using morbidity indicators from skeletons.

A. Life expectancy. Research on life expectancy from skeletons is limited by reliable estimates of age at death at advanced ages. The ages of children and young adults can be accurately determined from dental development and from the pattern of fusion in various growth plates, but the chronological sequence of skeletal changes is more subtle at older ages, and sometimes these changes are obscured by poor skeletal preservation following burial. Using techniques such as systematic changes in the public bone, some physical anthropologists lump ages beyond 50 into a single category. Others believe that the pattern of cranial suture closures is provides useful information at advanced ages. From one point of view, this limitation is modest because few people were likely to have survived beyond age 50 in most pre-modern societies. On the other hand, death rates rise rapidly at older ages, and the lack of reliable ages in this range significantly constrains the information available for estimating model life tables, thereby increasing confidence intervals. ${ }^{5}$ The outlook is promising, however, because new techniques based on systematic growth in tooth cementum (a hard tissue that 
covers the external surface of tooth roots) can provide highly accurate estimates of ages, even for very old adults.

Physical anthropologists know that the bones of infants and very young children are soft and frequently deteriorate after burial. Careful excavation is required to recount the deaths at these ages. Sometimes more limiting is the geographic dispersion of burials, so that excavations associated with new roads, buildings and other development projects recover only a portion of the deaths in any society. This is not a problem if people are missing at random, but it is an issue if infants or young children were buried in separate locations or there were seasonal places of residence.

Population growth rates were probably small in pre-modern times for continents or large regions, and on this scale the assumption of a stationary population is plausible. If correct and if all burials of a society are recovered and accurately aged, then life expectancy simply equals the average age at death. Any particular society, however, may have grown or shrunk from fluctuations in fertility or mortality relative to the regional or continental average. High birth rates, for example, increase the relative number of deaths at young ages. Compensation for these effects can be made if archaeological or other information is available as an ingredient to estimating fertility rates. While this is a new area of paleodemography, it is likely that considerable information gaps will remain for many burial sites.

One may reasonably suppose that life expectancy ranged from roughly 20 to 40 years for most societies prior to the late nineteenth century. Populations close to 20 years were highly stressed and would have vanished quickly without very high fertility, which would have been unlikely under the environmentally stressful conditions that produced high mortality. Life expectancy in excess of 40 years is rarely observed without good nutrition, or in its absence, is usually accompanied by aspects of the health revolution such as improved sanitation or other practices inspired by the germ theory of disease. With complete excavation of a society's burials, accurate age estimates and considerable archaeological information, it is reasonable to hope that life expectancy could be reliably placed into one of three categories within this range: 
low-to-mid 20s, high 20 s to low 30 s and mid-to-high 30 s. Yet, even this is quite useful information for understanding the quality of life in the past.

B. Morbidity. Skeletons are good at summarizing several types of chronic morbidity, with the exception of various soft-tissue conditions such as hernias or torn ligaments. Degenerative joint disease and dental decay often develop over many years, and both have adverse functional consequences. DJD is painful and limits mobility, whereas dental decay limits the ability to chew and digest a coarse diet, which impairs net nutrition, weakens the immune system, and increases vulnerability to illness. Signs of anemia (cribra orbitalia and porotic hyperostosis) usually appear early in childhood and the adverse environmental conditions that created these bony malformations tend to persist thereafter. Skeletal infections are often painful and signal a weakened immune system that can lead to illness and functional loss. Broken bones and weapon wounds are painful and require time to heal, and the loss of mobility or dexterity associated with them can be permanent if they heal in a misaligned fashion.

Stunting and linear enamel hypoplasias (LEH) are not direct measures of morbidity, but they signal a loss of functional capacity. Hunger is painful and limits physical activity in the fashion of anemia, and hypoplasias are usually the direct result of severe bouts of disease or malnutrition in early childhood. These skeletal lesions therefore index various types of morbidity.

C. Sampling issues. Physical anthropologists may have little control over the location and extent of an excavation if it is the result of a development project that clears a small area of ground. With the exception of the removal of entire cemeteries containing reasonably closed populations, one can seldom argue that skeletons represent an entire society. Many collections in Europe, for example, are disproportionately from cities and towns, where much construction has occurred relative to rural areas.

These constraints are a hindrance but far from disabling. In formulating a large comparative project involving numerous sites, one may stratify to obtain adequate representation from rural and urban areas. Post-weighting samples is a second option. As 
discussed below, one may sidestep age bias by converting information to age specific rates if the age distribution of deaths has been skewed by fertility, migration, or excavation.

D. A health index. At this stage of research, numerous simplifying assumptions and approximations are required to distill diverse skeletal data into a single number for comparative ranking and study of populations. ${ }^{6}$ Ideally both life expectancy and morbidity would be available, so that one might roughly approximate a measure such as quality-adjusted life years. Unfortunately, many sites in The Backbone of History, the largest comparative skeletal study undertaken to date, lack reliable estimates of life expectancy. Therefore the health index discussed here includes only morbidity as expressed in the frequency and severity of skeletal lesions, but the index could be modified to incorporate length of life. A positive correlation between morbidity and mortality is likely, however, which mitigates the lack of data on life expectancy in ranking health across sites.

The index was estimated from the 12,520 skeletons of individuals who lived at 65 localities in the Western Hemisphere over the past several thousand years (see the introduction to Steckel and Rose, 2002). For each individual, the 7 skeletal measures discussed above were graded on a scale of 0 (most severe expression) to 100 (no lesion or deficiency). Age-specific rates of morbidity pertaining to the health indicators during childhood (stature, LEH and anemia) were calculated by assuming that conditions persisted from birth to death, an assumption justified by knowledge that childhood deprivation is correlated with adverse health as an adult. ${ }^{7}$ The duration of morbidity prior to death is in fact unknown for the remaining 4 components (infections, trauma, DJD, and dental decay) and will be the subject of future research, but was approximated by an assumption of 10 years. Results are grouped into age categories of 0-4, 5-9, 10-14, 15-24, 25-34, 35-44 and 45+.

Next, the age-specific rates for each skeletal measure were weighted by the relative number of person-years lived in a reference population that is believed to roughly agree with pre-Columbian mortality conditions in the Western Hemisphere (Model West, level 4), and the results were multiplied by life expectancy in the reference population (26.4 years) and expressed as a percent of the maximum attainable (26.4, which corresponds to a complete lack 
of skeletal defects or lesions). The 7 components of the index were then weighted equally to obtain the overall index.

Numerous assumptions underlying the index can be challenged, modified and refined, which cannot be pursued in a short paper. It would be appropriate to weight the elements of the index, such as dental decay and trauma, by their functional consequences but this is complicated by the nature of the social safety net, medical technology and other factors that vary in unknown ways across societies. Thus, equal weighting is questionable but it is also difficult to justify an alternative scheme given the present state of knowledge. In addition, the index is an additive measure that ignores interactions, but having both a skeletal infection and trauma could have been worse than the sum of their independent effects on health.

\section{Plausibility of Results}

Comparing results with patterns well established in historical studies is a useful technique for assessing the health index as a work in progress. ${ }^{8}$ Settlement size is a suitable category of analysis; demographers widely report that mortality rates were higher in urban as opposed to rural areas prior to the adoption of public health measures inspired by the germ theory of disease.

Because European exploration and colonization distorted Native American mortality patterns in ways that could have obscured the effects of settlement size, comparisons are limited to pre-Columbian sites, which include skeletons of 4,078 individuals who lived at 23 localities in North, Central and South America. Archaeological evidence was used to arrange the settlements into three types: mobile (essentially hunter gatherers); village, or settled but dispersed populations; and town or paramount urban center. The estimated regression of the health index on settlement type is:

$$
\begin{aligned}
& \mathrm{HI}=78.98-8.71 \text { Village }-14.91 \text { Urban, } \mathrm{N}=23, \mathrm{R}^{2}=0.42 \\
& (0.000)(0.021) \quad(0.001)
\end{aligned}
$$

where significance levels are given in parentheses, and the mean and standard deviation of the dependent variable are 70.5 and 8.0 , respectively. 
That the health index systematically declined (by a roughly two standard deviations) as settlement size increased is welcome news. The index has passed an important preliminary test, suggesting it is credible even in its crude form. Presumably refinements in the methodology will sharpen the quantification of important aspects of health.

\section{Implications}

Although focus of the paper is methodology, it is worth mentioning results that challenge interpretations of the distant past. Some historians have noted the absence of many prominent European diseases such as smallpox, measles and typhoid in arguing that native populations were generally healthy, perhaps living in an epidemiological Garden of Eden. ${ }^{9}$ Such conditions might have allowed an enormous population to flourish. Instead, the skeletons examined with the health index reveal enormous diversity, with pre-Columbian Native Americans occupying the highest and the lowest slots in the rankings at 65 localities, which also include 14 groups of European-Americans and African Americans. The absence of several major European diseases does not prove there was a benign disease environment or good health in pre-Columbian America. Numerous native populations, particularly ones that lived late in the pre-Columbian period, were riddled with pathological lesions. The natives encountered by Columbus either brought or evolved with enough pathogens to shorten life and cause substantial morbidity.

\section{Research Frontiers}

Astronomy has been greatly invigorated by newly deployed telescopes, which allow observers to peer deep into space, gathering light emitted from vast distances and recording events early in the history of the universe. In a similar but smaller way, skeletons and related artifacts can be powerful for the social sciences, allowing observers to measure and analyze important aspects of social performance deep into human history, prior to the dawn of civilization. Neither astronomy nor economic history is an experimental science; both operate within the confines of observational evidence from which the intellectually curious can nevertheless learn much about astronomical or human origins and evolution. 
Study of skeletons can satisfy far more than natural intellectual curiosity about the contours of the human past, however. Not only a basic ingredient in the quality of life, health is intertwined with demographic, social, economic and political change and with the outcomes of wars and other conflicts. Health affects work capacity and the incentives to invest in skills that contribute to economic growth. Economists, historians and political scientists have identified inequality, not only in income or wealth, but also in the form of disparities in health and nutrition, as a driving force in social, political and economic change. Thus, health has played a central role in human history, both as an agent of change and as an outcome measure indicating the quality of life.

Skeletal health will be useful, for example, in debates over the prime movers of very long-term economic growth. A growing literature has sought to model technological progress as arising from endogenous choices of profit-maximizing innovators. Gary D. Hansen and Edward C. Prescott (1998) posit two technologies for producing output in which the constantreturns technology progressively supplants the diminishing returns technology. Oded Galor and David N. Weil (2000) conclude that there was a very long-lived growth path in which per capita consumption was constant, population grew slowly, and technology improved slowly. Eventually, the long-run features of technology kicked in, a demographic transition occurred, and a new growth path was approached. Charles I. Jones (2001) uses a model of fertility choice to argue that a strong positive relationship between income and fertility existed at low incomes but a negative relationship existed at moderate to high incomes. Jones combines these preferences with a technology that exhibits decreasing short-run returns to labor and weakly increasing long-run returns. Ultimately, the level of per capita income is determined by the condition that the induced level of fertility must just suffice for zero population growth.

Insofar as skeletal health is an adequate proxy for human welfare, it will be possible to test explanations flowing from this line of research. According to the Hansen/Prescott and Galor/Weil models, per capita consumption should have been essentially constant before the era of modern growth, but the Jones model allows for periods during which human welfare improved measurably because of bursts in innovative activity or unusually favorable 
institutional changes. Jones' model can therefore be regarded as proposing the alternative hypothesis to the null hypothesis proposed by the Hansen/Prescott and Galor/Weil models.

A second promising application concerns human adaptation to climate, a topic inspired by growing concerns over global warming. Using tree rings, ice cores and other sources, climate historians have made considerable progress in measuring important aspects of climate over many thousands of years (Fagan, 2000). Economists such as Jeffrey Sachs (2001) have engaged the debate over climate and economic performance, and climate historians such as Peter deMenocal (2001) have used the new evidence to link climate change to the fall of the Maya. While the fall of civilizations is interesting, it is a crude measure of social performance. By linking skeletal health with new climate data, it will be possible to measure the connection between climate and human welfare with greater precision. 


\section{References}

Barker, David James Purslove. Mothers, babies, and health in later life. Edinburgh: Churchill Livingstone, 1998.

Buikstra, Jane E. and Ubelaker, Douglas H. Standards for data collection from human skeletal remains. Fayetteville: Arkansas Archeological Survey, 1994.

deMenocal, Peter B. "Cultural Responses to Climate Change during the Late Holocene." Science April 27, 2001, 292, pp. 667-673.

Fagan, Brian. The Little Ice Age: How Climate Made History, 1300-1850. New York: Basic Books, 2002.

Fogel, Robert W. and Costa, Dora L. "A Theory of Technophysio Evolution, with Some Implications for Forecasting Population, Health Care Costs and Pension Costs.” Demography 1997(1), 34, pp. 49-66.

Galor, Oded and Weil, David N. "Population, Technology, and Growth: From Malthusian Stagnation to the Demographic Transition and Beyond." American Economic Review, 2000, 90(4), pp. 806-828.

Goodman, Alan S. and Martin, Debra L. "Reconstructing Health Profiles from Skeletal Remains," in Richard H. Steckel and Jerome C. Rose, eds., The backbone of history: health and nutrition in the Western Hemisphere. New York: Cambridge University Press, 2002, pp. 11-60.

Hansen, Gary D., and Prescott, Edward C. "Malthus to Solow.” National Bureau of Economic Research Working Paper No. 6858, 1998.

Jones, Charles I. "Was an Industrial Revolution Inevitable? Economic Growth Over the Very Long Run.” National Bureau of Economic Research Working Paper No. 7375, 1999.

Kiple, Kenneth F., and Beck, Stephen V., eds. Biological consequences of the European expansion, 1450-1800. Brookfield, Vt.: Ashgate, 1997. 
Larsen, Clark Spencer, Bioarchaeology: interpreting behavior from the human skeleton. Cambridge: Cambridge University Press, 1997.

Sachs, Jeffrey D. “Tropical Underdevelopment.” National Bureau of Economic Research Working Paper No. 8119, 2001.

Steckel, Richard H. "Stature and the Standard of Living." Journal of Economic Literature, 1995, 33(4), pp. 1903-40.

Steckel, Richard H., and Rose, Jerome C., eds. The backbone of history: health and nutrition in the Western Hemisphere. New York: Cambridge University Press, 2002.

Steckel, Richard H., Sciulli, Paul W. and Rose, Jerome C. “A Health Index from Skeletal Remains," in Richard H. Steckel and Jerome C. Rose, eds., The backbone of history: health and nutrition in the Western Hemisphere. New York: Cambridge University Press, 2002, pp. 61-93.

Tanner, James M., Fetus into Man: Physical Growth from Conception to Maturity. Cambridge: Harvard University Press, 1978.

Trotter, Mildred and Gleser, Goldine C. "Estimation of Stature from Long Bones of American Whites and Negroes." American Journal of Physical Anthropology, 1952, 10(4). pp. 463514.

White, Tim D. and Folkens, Pieter A. Human osteology. New York: Academic Press, 2000. 


\section{Footnotes}

${ }^{1}$ For discussion and references to the literature, see Tim D. White and Pieter A. Folkens (2000) and Alan S. Goodman and Debra L. Martin (2002).

${ }^{2}$ Clark Spencer Larsen (1997, p. 195).

${ }^{3}$ James M. Tanner (1978); Richard H. Steckel (1995).

${ }^{4}$ For a discussion see Jane E. Buikstra and Douglas H. Ubelaker (1994).

${ }^{5}$ There is also the problem of selecting a suitable model life table, which is complicated by lack of detailed information on age patterns of death in ancient populations. One can make informed conjectures but this adds to the uncertainty of results.

${ }^{6}$ A short paper necessarily conveys only a flavor of the methodology; for additional details and justification see Steckel, Paul W. Sciulli, and Rose (2002). Presumably future research will lead to more appropriate assumptions and an improved health index.

${ }^{7}$ The effect of fetal and early childhood health on adult health is sometimes called the Barker hypothesis (Barker, 1998). For a general discussion see Robert W. Fogel and Dora L. Costa (1997, 56-

$57)$.

${ }^{8}$ Various types of sensitivity analysis and formulation of standard errors are also planned, following public reaction to the methodology of the health index.

${ }^{9}$ For a general discussion of health in pre-Columbian America see Kenneth F. Kiple and Stephen V. Beck (1997). 